\title{
The precipitation chemistry and acidity over China during 2018
}

\author{
Xiaofang Jia ${ }^{1}$, Jie Tang ${ }^{1}$ and Yong Zhang ${ }^{1 *}$ \\ ${ }^{1}$ Meteorological Observation Center of China Meteorological Administration, Beijing 100081, China
}

\begin{abstract}
This paper reports the acid rain observation data from 376 Acid Rain Monitoring stations and the precipitation chemistry data from 5 Global Atmosphere Watch stations of China Meteorological Administration(CMA) during 2018. The variation characteristics of acid rain in China and that of precipitation chemistry in Eastern China are discussed. The results show that the acid rain area in China is mainly distributed in the Southeast and South of China and dispersively in North and Southwest of China. Heavy acid rain area is only limited in Eastern part of Hunan province. The annual mean precipitation $\mathrm{pH}$ value of all stations in 2018 ranges from 3.73 to 8.07 and the national annual mean precipitation $\mathrm{pH}$ value is 5.94, which is higher than those of 2010-2017. The national annual mean precipitation conductivity is $47.7 \mu \mathrm{S} \cdot \mathrm{cm}^{-1}$ with the higher conductivity in Northern China and lower in Southern China. Compared with 2010-2017, the acid rain pollution situation over China has been improving nationwide. The precipitation chemistry data shows that the concentration of sulfate is close to nitrate in precipitation and keeps decreasing in recent years.
\end{abstract}

\section{Introduction}

Precipitation is the most effective scavenging factor for removing particulate and dissolved gaseous pollutants from the atmosphere[1]. The acidity of the precipitation reflects the chemical composition of the atmosphere. The acid rain is causing damage to crops, trees and buildings. China is one of the countries with serious acid rain pollution. To tackle acid rain pollution, the Chinese State Council has implemented Atmospheric Pollution Prevention and Control Act in 1995. After that, the control of $\mathrm{SO}_{2}$ emission is enacted in 1998, known as Two Control Zone (TCZ)[2]. In the period of 1995-1999, the precipitation acidity at most of the sites remained steady or showed a decreasing trend[3]. But with the rapid increases of $\mathrm{SO}_{2}$ and $\mathrm{NO}_{\mathrm{X}}$ emissions in Eastern China there is the enhanced acidification during 20002006[3]. The recent research indicates that the relative change rates of China's anthropogenic emissions during 2010-2017 are estimated as follows:-62\% for $\mathrm{SO}_{2}$, $17 \%$ for $\mathrm{NO}_{\mathrm{X}},+1 \%$ for $\mathrm{NH}_{3}$ [4]. However, there have been few reports on the general trend of acid rain changes across the country. It is important to evaluate how these actions have influenced the acid rain trends. The purpose of this study is to present the most updated status of acid rain over China and the changing characteristics in precipitation chemistry in 2018.

\section{Observation and data}

The precipitation acidity and conductivity are observed at 376 acid rain stations of China Meteorological
Administration. The instrumentation, sampling, measurement, and other operations are all regulated by the standard operation manual issued by CMA[5]. The daily precipitation is collected from 8:00 everyday to 8:00 the next day using polyethylene polymer buckets of $40 \mathrm{~cm}$ diameter. When the rainfall reaches $1.0 \mathrm{~mm}$, it is required for the $\mathrm{pH}$ and conductivity measurements using a $0.01 \mathrm{pH}$ meter and 1.0 conductivity meter. The chemical components in the precipitation samples are measured at 5 background stations (Shangdianzi in Beijing, Longfengshan in Heilongjiang, Lin'an in Zhejiang, Jinsha in Hubei, Waliguan in Qinghai). The precipitation samples of the 5 stations are sent to the laboratory of Meteorological Observation Center of China Meteorological Administration at low temperature for analysis. $\mathrm{Ca}^{2+}, \mathrm{Na}^{+}, \mathrm{K}^{+}$and $\mathrm{Mg}^{2+}$ are analyzed by ZA3300 atomic absorption spectrophotometer (ITACHI, Japan), $\mathrm{NH}_{4}{ }^{+}, \mathrm{SO}_{4}{ }^{2-}, \mathrm{NO}_{3}{ }^{-}, \mathrm{CI}^{-}, \mathrm{F}^{-}$are analyzed by ICS$5000+$ ion chromatography system (Thermo, USA).

The precipitation data comes from the routine ground meteorological observations.

\section{The precipitation $\mathrm{pH}$ and conductivity in 2018}

\subsection{Spatial distribution}

The average annual precipitation $\mathrm{pH}$ in 376 stations is 5.94 with the annual average $\mathrm{pH}$ value of the station ranging from 3.73 to 8.07 during 2018. Figure 1a shows the distribution of precipitation $\mathrm{pH}$ values over China in 2018. The acid rain areas $(\mathrm{pH}<5.6)$ in China are mainly

$\overline{\text { *Corresponding author's e-mail: yzhang@cma.gov.cn }}$ 
distributed in the Southeast, South of China and partly in North and Southwest of China. The severe acid rain area with $\mathrm{pH}$ value between 4.5 and 5.0 appears in the Southeast of Hunan province, Northwestern of Jiangxi province and in some parts of Chongqing and Guangdong province sporadically. Although the northern cities in China are heavily polluted by $\mathrm{SO}_{2}$, there are

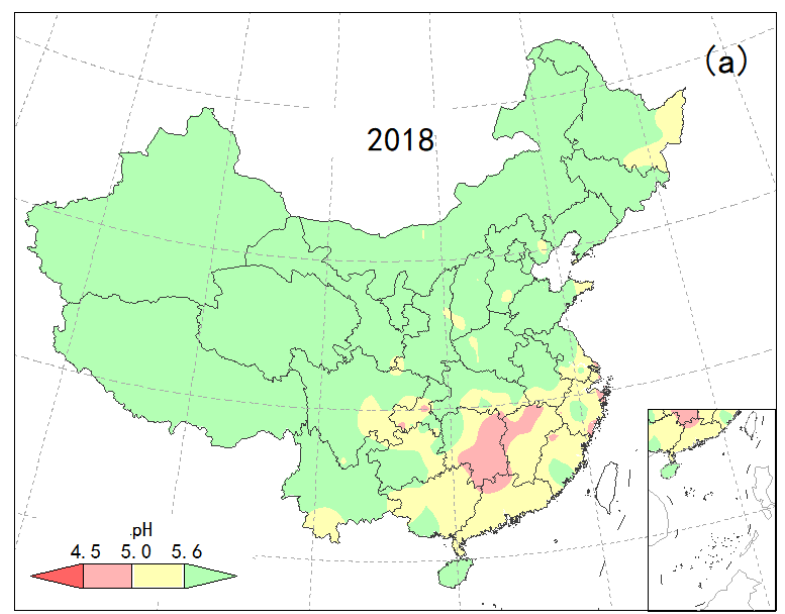

Figure 1. The precipitation $\mathrm{pH}(\mathrm{a})$ and conductivity(b) in 2018.

The average annual precipitation conductivity of the 376 stations is $47.7 \mu \mathrm{S} \cdot \mathrm{cm}^{-1}$ with the higher precipitation conductivity in the North and lower in the South(Figure 1b). Generally, the precipitation conductivity in most northern of the country is higher than $50.0 \mu \mathrm{S} \cdot \mathrm{cm}^{-1}$, but especially higher than $100.0 \mu \mathrm{S} \cdot \mathrm{cm}^{-1}$ in Xinjiang Province and most parts of Inner Mongolia. The precipitation conductivity of the most southern parts of China is lower than $50.0 \mu \mathrm{S} \cdot \mathrm{cm}^{-1}$. Among them, the precipitation conductivity of some parts in Fujian, Guangxi, Yunnan, Zhejiang, Guangdong, Sichuan provinces are lower than $25.0 \mu \mathrm{S} \cdot \mathrm{cm}^{-1}$. The different characteristics of conductivity among the North and South may due to the different characteristics of rainfall.

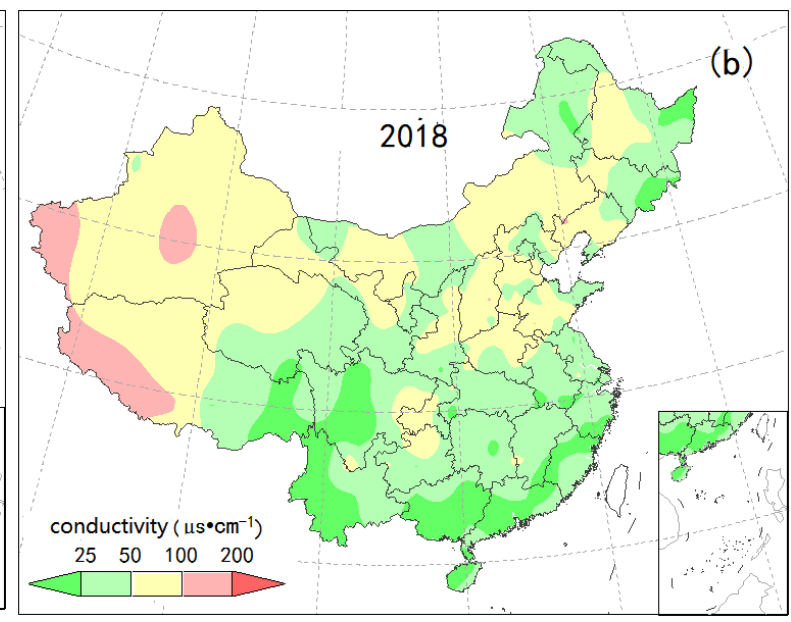

rarely no acid rain in the north of China. That is probably because the formation of acid rain depends not only on a fixed amount of $\mathrm{SO}_{2}$, but also on the buffering capacity of air[6]. Higher concentration of alkaline particulates and ammonia may be attributed to higher $\mathrm{pH}$ in the north of China.

Higher rainfall in the South makes the pollutants in the precipitation diluted.

\subsection{The annual mean $\mathrm{pH}$ of precipitation}

Figure 2 shows the time series of the national annual mean precipitation $\mathrm{pH}$ (NAMP $\mathrm{pH}$ )over China together with the $\mathrm{SO}_{2}$ and $\mathrm{NO}_{\mathrm{X}}$ emissions [4] which are the major acidic pollutants resulting in acid rain. The NAMP $\mathrm{pH}$ is derived from all annual mean $\mathrm{pH}$ of individual acid rain station. It is found that the NAMP $\mathrm{pH}$ declines in the most of the time with the emissions reduced. The correlation coefficient between $\mathrm{pH}$ and $\mathrm{SO}_{2}$ is 0.97 , while 0.89 for $\mathrm{NO}_{\mathrm{X}}$. The emissions of $\mathrm{SO}_{2}$ and $\mathrm{NO}_{\mathrm{X}}$ in 2014 is significantly reduced, and the precipitation $\mathrm{pH}$ increases most. The reduction of emissions are the main reason for the increased annual $\mathrm{pH}$. 


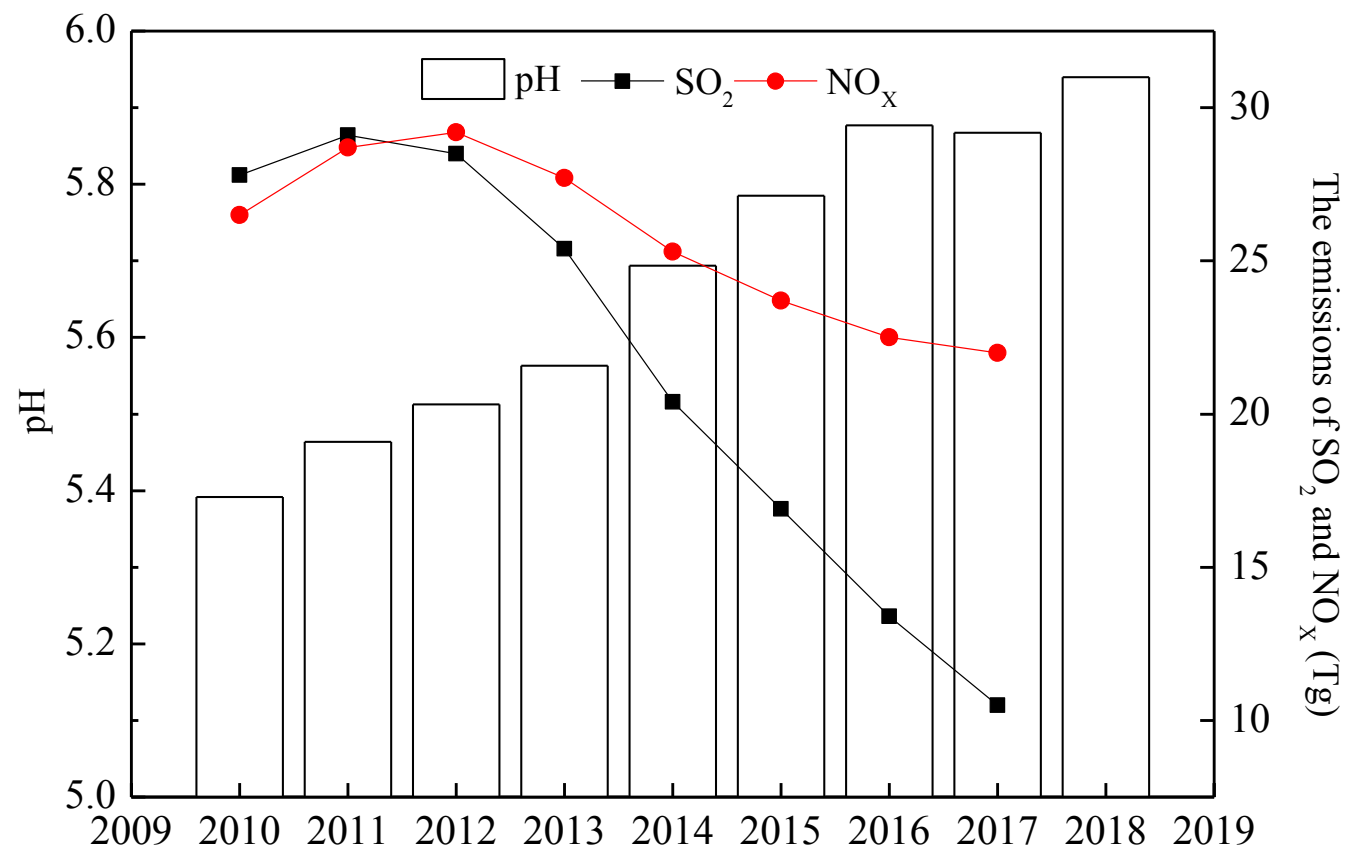

Figure 2. The annual mean $\mathrm{pH}$ and emissions of $\mathrm{SO}_{2}$ and $\mathrm{NO}_{\mathrm{X}}$ from 2010 to 2018.

\section{The ionic composition precipitation in 2018}

\subsection{Overall statistical characteristics}

Table 1 shows the chemical composition of precipitation samples from 5 background stations. It can be seen that the precipitation acidity differs with higher $\mathrm{pH}$ at Waliguan and Longfengshan in the north of China, while with lower $\mathrm{pH}$ at Shangdianzi, Lin'an and Jinsha located in the Beijing-Tianjin-Hebei and Yangtze River region where are the most industrial and urbanized areas in China.

The total concentration of anions and cations in the precipitation at the 5 atmospheric background observation stations are 73.4-140.1 and 97.2-266.2 $\mu \mathrm{mol} \cdot \mathrm{L}^{-1}$, respectively. In addition, the different total concentration of anions and cations at the 5 sites reflects the different concentration levels of precipitation components at different sites. Among them, the total concentration of anions and cations at Waliguan is the highest where the precipitation is scarce. In contrast the rainfall at Lin'an is abundant and the total concentrations of anions and cations are lowest.

Although different concentration levels of $\mathrm{SO}_{4}{ }^{2-}$ and $\mathrm{NO}_{3}{ }^{-}$in different stations, the $\mathrm{SO}_{4}{ }^{2-}$ and $\mathrm{NO}_{3}{ }^{-}$are predominant among anions in all the stations, which means that acid rain in China nowadays results from $\mathrm{SO}_{2}$ and $\mathrm{NO}_{\mathrm{X}}$ pollution. The $\mathrm{SO}_{4}{ }^{2-} / \mathrm{NO}_{3}{ }^{-}$reflects the relative contribution of $\mathrm{SO}_{2}$ and $\mathrm{NO}_{\mathrm{X}}$ to the precipitation acidity. The $\mathrm{SO}_{4}{ }^{2-} / \mathrm{NO}_{3}{ }^{-}$at Waliguan, Shangdianzi, Lin'an, Longfengshan and Jinsha are 2.15, 1.05, 0.90, 1.15 and 1.46, respectively. At Lin'an the concentration of $\mathrm{NO}_{3}{ }^{-}$is higher than $\mathrm{SO}_{4}{ }^{2-}$, which may indicates $\mathrm{NO}_{\mathrm{X}}$ pollution are more and more important than $\mathrm{SO}_{2}$ in this area and it is consistent with the significant reduction in $\mathrm{SO}_{2}$ emissions.

$\mathrm{NH}_{4}{ }^{+}$and $\mathrm{Ca}^{2+}$ are the main ions. The ratio of $\mathrm{NH}_{4}^{+}$ concentration to $\mathrm{Ca}^{2+}$ concentration reflects the relative contribution of the two main basic components to neutralize the precipitation acidity. $\mathrm{NH}_{4}{ }^{+} / \mathrm{Ca}^{2+}$ is highest at Shangdianzi(1.52), than followed by Longfengshan(0.81), Lin'an(0.73), Jinsha(0.27), and lowest at Waliguan $(0.21)$. It is worth noting that the concentration of $\mathrm{NH}_{4}^{+}$in the precipitation is very high at Shangdianzi, which may be related to agricultural activities around the station. Meanwhile elevated $\mathrm{NH}_{3}$ levels in Shangdianzi coincides with elevated $\mathrm{NH}_{4}^{+}[7]$, indicating that $\mathrm{NH}_{3}$ likely mitigates acid rain pollution in the area. The concentration of $\mathrm{Ca}^{2+}$ is highest at Waliguan which may be attributed to the dry climate and less precipitation. In addition, the elevated $\mathrm{Ca}^{2+}$ levels in Jinsha may because the construction activities around the site.

Table 1. The precipitation chemical ionic composition during $2018\left(\mu \mathrm{mol} \cdot \mathrm{L}^{-1}\right)$.

\begin{tabular}{ccccccccccc}
\hline Stations & $\mathrm{pH}$ & $\mathrm{F}^{-}$ & $\mathrm{Cl}^{-}$ & $\mathrm{NO}_{3}^{-}$ & $1 / 2 \mathrm{SO}_{4}^{2-}$ & $\mathrm{NH}_{4}^{+}$ & $\mathrm{K}^{+}$ & $\mathrm{Na}^{+}$ & $1 / 2 \mathrm{Ca}^{2+}$ & $1 / 2 \mathrm{Mg}^{2+}$ \\
\hline $\begin{array}{c}\text { Waliguan } \\
(36.3 \mathrm{~N}, 100.9 \mathrm{E})\end{array}$ & 6.13 & 4.3 & 21.0 & 24.6 & 52.9 & 37.1 & 5.8 & 28.3 & 175.4 & 19.7 \\
$\begin{array}{c}\text { Shangdianzi } \\
(40.7 \mathrm{~N}, 117.1 \mathrm{E})\end{array}$ & 5.54 & 2.6 & 7.7 & 49.4 & 51.9 & 107.2 & 1.8 & 4.4 & 70.4 & 11.5
\end{tabular}




\begin{tabular}{ccccccccccc}
$\begin{array}{c}\text { Lin'an } \\
(30.3 \mathrm{~N}, 119.7 \mathrm{E})\end{array}$ & 4.78 & 1.6 & 7.8 & 33.7 & 30.4 & 37.1 & 1.0 & 3.3 & 50.9 & 5.0 \\
$\begin{array}{c}\text { Longfengshan } \\
(44.7 \mathrm{~N}, 127.6 \mathrm{E})\end{array}$ & 5.33 & 1.7 & 9.2 & 29.1 & 33.4 & 46.5 & 6.2 & 14.2 & 57.3 & 8.0 \\
$\begin{array}{c}\text { Jinsha } \\
(29.4 \mathrm{~N}, 114.1 \mathrm{E})\end{array}$ & 4.88 & 3.2 & 21.1 & 47.1 & 68.6 & 35.7 & 15.4 & 18.3 & 134.5 & 16.1 \\
\hline
\end{tabular}

\subsection{The temporal distribution characteristics}

Table 2 shows the major precipitation ions concentrations at the 3 atmospheric background stations in the eastern part of China where heavy acid rain pollution occurs in different years. It can be seen that there is a decreasing trend in the main ionic components in precipitation, and the $\mathrm{SO}_{4}{ }^{2-} / \mathrm{NO}_{3}{ }^{-}$also shows a downward trend. It is closely related to China's emission reduction in recent years, controlling nitrogen oxides and sulphide emissions. In addition, the decline in $\mathrm{SO}_{4}{ }^{2-} / \mathrm{NO}_{3}{ }^{-}$ also reflects that the acid rain in China has changed from driven by $\mathrm{SO}_{2}$ to by $\mathrm{SO}_{2}$ and $\mathrm{NO}_{2}$ both.

Table 2. The concentration of chemical component in $\operatorname{precipitation}\left(\mu \mathrm{mol} \cdot \mathrm{L}^{-1}\right)$.

\begin{tabular}{cccccccc}
\hline Stations & Period & $1 / 2 \mathrm{SO}_{4}^{2-}$ & $\mathrm{NO}_{3}{ }^{-}$ & $\mathrm{NH}_{4}^{+}$ & $1 / 2 \mathrm{Ca}^{2+}$ & $\mathrm{S} / \mathrm{N}$ & literature \\
\hline \multirow{3}{*}{ Shangdianzi } & $1990-1997$ & 90.0 & 114.4 & 43.3 & 60.2 & 0.8 & {$[8]$} \\
& $1999-2004$ & 161.5 & 93.3 & 68.6 & 71.8 & 1.7 & {$[9]$} \\
& 2018 & 51.9 & 49.4 & 107.2 & 70.4 & 1.05 & This paper \\
Longfengshan & $1991-1997$ & 46.5 & 29.2 & 18.8 & 17.1 & 1.6 & {$[8]$} \\
& 2018 & 33.4 & 29.1 & 46.5 & 57.3 & 1.15 & This paper \\
& $1985-1997$ & 107.1 & 32.3 & 24.0 & 8.3 & 3.3 & {$[8]$} \\
Lin'an & $2006-2009$ & - & - & - & - & 1.7 & {$[10]$} \\
& 2018 & 30.4 & 47.1 & 37.1 & 50.9 & 0.65 & This paper \\
\hline
\end{tabular}

In order to analyze the changes in the chemical composition of precipitation in China, table 3 shows the seasonal variation of the precipitation components of the 3 background stations in the eastern part of China. In general, the concentration of inorganic ions in precipitation is relatively lower in summer months and relatively higher in winter months. The pollutants in the atmosphere are washed and diluted with more precipitation in summer. In addition less pollutants are emitted in summer. Less $\mathrm{SO}_{4}{ }^{2-}$ and $\mathrm{NO}_{3}{ }^{-}$is found in summer due to the less $\mathrm{SO}_{2}$ and $\mathrm{NO}_{\mathrm{X}}$ emissions. Higher $\mathrm{SO}_{4}{ }^{2-}$ and $\mathrm{NO}_{3}^{-}$occurs in winter, especially at Shangdianzi and Longfengshan where cold weather generates more fossil fuel combustion. Higher $\mathrm{Ca}^{2+}$ concentrations appears at Shangdianzi and Longfengshan in spring where frequent sandstorms occurs. The concentration of $\mathrm{NH}_{4}{ }^{+}$is generally lower in the summer months, and it is mainly related to decomposition of $\mathrm{NH}_{4}{ }^{+}$at the high temperature in summer.

Table 3. The concentrations of major ions in precipitation $\left(\mu \mathrm{mol} \mathrm{L}^{-1}\right)$.

\begin{tabular}{cccccc}
\hline \multirow{2}{*}{ Stations } & Season & \multicolumn{4}{c}{ Ionic concentration } \\
\cline { 3 - 6 } & & $1 / 2 \mathrm{SO}_{4}{ }^{2-}$ & $\mathrm{NO}_{3}{ }^{-}$ & $\mathrm{NH}_{4}{ }^{+}$ & $1 / 2 \mathrm{Ca}^{2+}$ \\
\hline \multirow{3}{*}{ Shangdianzi } & Spring & 116.4 & 101.6 & 164.4 & 254.2 \\
& Summer & 62.6 & 63.4 & 146.1 & 80.3 \\
& Autumn & 95.1 & 141.6 & 196.3 & 147.4 \\
& Winter & - & - & - & - \\
\multirow{3}{*}{ Longfengshan } & Spring & 108.9 & 112.6 & 141.3 & 225.1 \\
& Summer & 28.2 & 25.7 & 54.7 & 32.1 \\
& Autumn & 27.4 & 16.2 & 23.0 & 59.2 \\
& Winter & 98.5 & 87.8 & 129.3 & 98.8 \\
& Spring & 52.8 & 65.4 & 70.2 & 44.6 \\
Lin'an & Summer & 15.1 & 18.0 & 20.7 & 91.0 \\
& Autumn & 45.8 & 57.8 & 52.4 & 80.0 \\
& Winter & 42.5 & 45.6 & 39.4 & 90.0 \\
\hline
\end{tabular}




\section{Conclusions}

a) The acid rain area is mainly distributed in the Southeast, South of China and partly in North and Southwest of China. Compared with the average situation from 2010 to 2017 , the $\mathrm{pH}$ of precipitation is significantly higher. The precipitation acidity significantly decreases and the acid rain pollution is improved in China in 2018.

b) The inorganic ion concentration in precipitation at 5 background stations in China is different, but the main ionic components in precipitation in Eastern China decreases. The decline in $\mathrm{SO}_{4}{ }^{2-} / \mathrm{NO}_{3}{ }^{-}$reflects that the acid rain in China has changed from driven by $\mathrm{SO}_{2}$ to by $\mathrm{SO}_{2}$ and $\mathrm{NO}_{2}$ both.

\section{Acknowledgments}

The authors wish to thank those working at the CMAARMN stations for their efforts in the long-term observation of acid rain.

\section{References}

1. Alkhashman, O.. (2005)Study of chemical composition in wet atmospheric precipitation in Eshidiya area, Jordan. Atmospheric Environment, 39(2005):6175-6183.

2. Liu, B., Hao, J., He, K., et al.. (1998)Study on designation of acid rain and $\mathrm{SO}_{2}$ pollution control areas and policy implementation. China Environmental Science, 18(4):1-7.

3. Tang, J., Xu, X., Ba, J., et al.. (2010)Trends of the precipitation acidity over China during 1992-2006. Chinese Science Bulletin, 55(17):1800-1807.

4. Zheng, B., Tong, D., Li, M., et al.. (2018)Trends in China's anthropogenic emissions since 2010 as the consequence of clean air actions. Atmospheric Chemistry and Physics, 18:14095-14111.

5. China Meteorological Administration. (2005)Manual for Acid Rain Monitoring (in Chinese). Meteorological publishing, Beijing.

6. Zhao, D. and Sun, B.. (1986)Air Pollution and Acid Rain in China. Ambio, 15(1):2-5.

7. Meng, Z., Xu, X., Lin, W., et al.. (2018)Role of ambient ammonia in particulate ammonium formation at a rural site in the North China Plain. Atmospheric Chemistry and Physics, 18:167-184.

8. Yang, D., Zhou, H., and Zhang Z. (2002)Chemical characteristics of precipitation in regional air pollution background stations of China(in Chinese). Quarterly Journal of Applied Meteorlolgy, 13(4):430-439.

9. Xu, J., Zhang, X., Xu, X., et al. (2008)Variations and source identification of chemical compositions in wet deposition at Shangdianzi background station(in Chinese). Acta Scientiae Circumstantiae, 28(5):1001-1006.
10. Zhao, W., Kang, L., Lin, H., et al. (2012)Characteristics and affecting factors analysis of acid rain at Lin'an atmosphere watch regional station(in Chinese). Environmental Monitoring in China, 28(4):9-13. 